\title{
JOGO DA MEMÓRIA DAS FUNÇÕES OXIGENADAS (MemOxi)
}

\author{
Apresentação: Pôster
}

Ayrton Matheus da Silva Nascimentoํㅜㄹ Natália Kelly da Silva Araújo²; Rafaela Germânia Barbosa de Araújo ${ }^{3}$; Flávio José de Abreu Moura ${ }^{4}$; Kilma da Silva Lima Viana ${ }^{5}$

\section{Introdução}

Os jogos didáticos aliam o aprendizado de determinados conteúdos à atividade lúdica, despertando interesse dos estudantes nos conteúdos discutidos e propiciando uma aprendizagem eficaz, divertida e empolgante. A precípua utilidade do uso de jogos didáticos envolve a motivação, desenvolvida pelo desafio, acarretando o acréscimo de estratégias de resolução de dúvidas, a avaliação das decisões tomadas e a familiarização com termos e concepções apresentadas.

Os jogos são indicados como um tipo de recurso didático educativo que podem ser utilizados em momentos distintos, como na apresentação de um conteúdo, ilustração de aspectos relevantes ao conteúdo, como revisão ou síntese de conceitos importantes e avaliação de conteúdos já desenvolvidos (CUNHA, 2004).

De acordo com Vieira et al. (2016) é importante reafirmar que há muitas possibilidades de inovação no que diz respeito ao ensino-aprendizagem e que apesar das dificuldades encontradas, é preciso ter em mente que as mesmas são desafios pertinentes à docência. Abordar os jogos didáticos como uma metodologia em sala de aula é uma maneira divertida e ao mesmo tempo instrutiva.

\section{Fundamentação Teórica}

Diante alguns estudos, percebesse as dificuldades no processo de ensino-aprendizagem de Química. Normalmente os professores encontram-se presos na metodologia tradicional e os alunos costumam ter aversão aos conteúdos desta disciplina, por considerá-los de difícil compreensão. Essa realidade obriga-nos a uma busca incessante por alternativas que possam reverter ou modificar essa realidade do ensino de química. Muitos estudos têm sido realizados, com o objetivo de encontrar alternativas que possam melhorar o ensino de Química.

\footnotetext{
${ }^{1}$ Aluno de Pós - Graduação em Ciências de Materiais, UFPE - campus Recife, ayrthon.matheus@gmail.com

${ }^{2}$ Licencianda em Química, IFPE - campus Vitória, nataliakellybs@gmail.com

${ }^{3}$ Licencianda em Química, IFPE - campus Vitória, rafaelagermania@hotmail.com

${ }^{4}$ Licenciando em Química, IFPE - campus Vitória, flavio.jose33@hotmail.com

${ }^{5}$ Doutora em Ensino de Ciências, UFPE - campus Recife, kilma.viana@vitoria.ifpe.edu.br
} 
Segundo Kishimoto (1994), o jogo, considerado um tipo de atividade lúdica, possui duas funções: a lúdica e a educativa, e elas devem estar em equilíbrio, pois se a função lúdica prevalecer, não passará de um jogo e se a função educativa for predominante será apenas um material didático.

O jogo oferece estímulo e o ambiente necessários para propiciar o desenvolvimento espontâneo e criativo dos alunos além de permitir que o professor amplie seus conhecimentos sobre técnicas ativas de ensino e desenvolva suas capacidades pessoais e profissionais, estimulando-o a recriar sua prática pedagógica (BRASIL, 1999).

Vários autores têm apresentado jogos e destacado sua eficiência para despertar o interesse dos alunos pela Química (SCHRECK \& LANG, 1985; CRUTE, 2000; ELCHLER et al, 2000, 2005; SANTANA \& PASSOS, 2004; SOARES, 2004; entre outros). A maioria desses autores destaca os jogos como elementos motivadores e facilitadores do processo de ensino e aprendizagem de conceitos científicos.

\section{Metodologia}

A pesquisa terá uma abordagem qualitativa, pois está mais preocupada em compreender o processo do que fazer levantamento estatístico ou generalizações. Os sujeitos são 41 alunos voluntários do PDVL (Programa Internacional Despertando Vocações para Licenciaturas), na Escola de Referência em Ensino Médio Antônio Dias Cardoso, parceira do programa. O PDVL tem o objetivo de despertar interesse nos alunos pela licenciatura em Química.

Para desenvolvimento dessa intervenção utilizamos como base metodológica o ciclo da experiência Kellyana (CEK), que faz parte da Teoria dos Construtos Pessoais de George Kelly (1963), onde o Ciclo da Experiência Kellyana é dividida em cinco etapas: (i) Antecipação, (ii) Investimento, (iii) Encontro, (iv) Confirmação ou Desconfirmação e (v) Revisão Construtiva.

\section{Resultados e Discussões}

\section{Jogo de Memória das Funções Oxigenadas (MemOxi)}

$\checkmark$ MemOxi: tem a missão de unir os grupos funcionais com a estrutura e a nomenclatura das funções oxigenadas de forma atrativa e divertida.

\section{"Regras do Jogo":}

$\mathbf{1}^{\circ}$ Passo: Formar grupos de 04 pessoas, para jogar ficar opcional a formação, ou seja, pode cada um jogar individualmente, ou formar duas duplas;

$\checkmark \quad \mathbf{2}^{\circ}$ Passo: Tira par ou ímpar para quem inicia a partida; 
$3^{\circ}$ Passo: Quem ganhou inicia, logo os estudantes recebem as orientações de como formar os "PARES", porque o jogo é formado por duas fases, a primeira é jogada com as cartas (01 e 02) e a segunda com as cartas (02 e 03), o jogo apresenta 03 (três) tipos de cartas (Carta 01 - Carta das Estruturas do Grupo Funcional das Funções Oxigenadas - Figura 01), (Carta 02 - Carta dos Grupos Funcionais das Funções Oxigenadas - Figura 02), e (Carta 03 Carta das Nomenclatura do Grupo Funcional das Funções Oxigenadas - Figura 03), após as orientações inicia-se a partida;

$\checkmark \quad 4^{\circ}$ Passo: Inicia-se a primeira fase do jogo, O primeiro jogador vira uma carta, caso for a carta 01, em seguida escolhe outra carta, caso for a carta e ligação estiver correta, ou seja, forma um par, ele as guarda e joga novamente;

$\checkmark \quad 5^{\circ}$ Passo: Ao errar devolve a peça no mesmo lugar e a vez passa para o jogador que estiver a usa esquerda, em sentido horário, que irá fazer sua movimentação de peças, de mesmo modo;

$\checkmark \quad 6^{\circ}$ Passo: Os próximos jogadores repetem a dinâmica, e a jogada segue adiante, até voltar ao primeiro jogador ou até o término dos pares ocultos;

$\checkmark \quad \mathbf{7}^{\mathbf{0}}$ Passo: Depois de algumas rodadas, os jogadores irão começar a memorizar lentamente as formulas, nomenclaturas e as posições das devidas peças, tornando mais fácil encontrar os pares;

$\checkmark \quad 8^{\circ}$ Passo: Quando estiver sobrando cerca de um terço das peças é aconselhável que as embaralhem novamente dificultando um pouco mais o jogo e aumentando a competitividade;

$9^{\circ}$ Passo: O vencedor será aquele que contabilizar mais pares sob seu poder quando todas os pares forem encontrados;

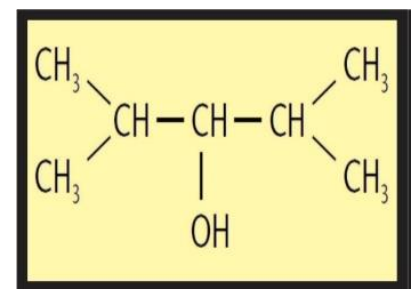

Figura 01: Modelo de Carta das Estruturas do Grupo Funcional (Álcool) - Fonte: Autor (2016) 


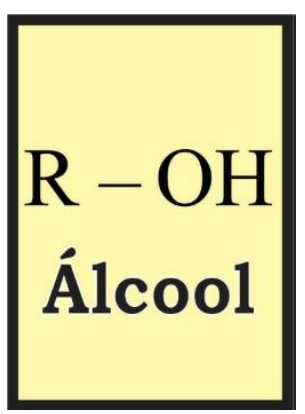

Figura 02: Modelo de Carta do Grupo Funcional (Álcool) - Fonte: Autor (2016)

\section{2,4 dimetiti-pentan-3.0)}

Figura 03: Modelo de Carta da Nomenclatura do Grupo Funcional (Álcool) - Fonte: Autor (2016)

$\checkmark \quad 1^{\text {a }}$ Etapa - Antecipação: Neste momento realizamos uma "Avaliação Diagnóstica I" com os estudantes, onde nesta avaliação continha 04 perguntas sobre o conteúdo de "Funções Oxigenadas", onde foi elaborado o jogo "MemOxi - Jogo da Memória das Funções Oxigenadas", na qual nesta avaliação os exercícios pediam para construir e identificar nas estruturas as funções oxigenadas.

$\checkmark \quad 2^{\text {a }}$ Etapa - Investimento: Neste momento foi concretizado uma explicação do conteúdo referente à temática do jogo, com alguns compostos orgânicos do cotidiano, e de forma dinâmica fazendo questionamentos aos alunos e levando em interesse suas hipóteses iniciais. Através disso, os sujeitos foram engajados no processo de investimento acerca da proposição em questão.

$\checkmark \quad 3^{\text {a }}$ Etapa - Encontro: Neste momento, foi realizado com os estudantes a aplicação do jogo "MemOxi”" e as suas regras;

$\checkmark \quad 4^{\text {a }}$ Etapa - Confirmação ou Desconfirmação: Neste momento, os alunos foram questionados novamente para que pudessem confirmar ou desconfirmar as suas hipóteses iniciais;

$5^{\text {a }}$ Etapa - Revisão Construtiva: Neste momento citamos alguns exemplos das Avaliação Diagnóstica I, e questionamos sobre os grupos funcionais das funções oxigenadas para ver se os estudantes conseguem diferenciar os grupos funcionais, e com a ajuda do jogo, percebemos que associaram a nomenclatura e estrutura com os grupos funcionais. Foi possível verificar, dessa forma que houve uma mudança sobre o que os estudantes pensavam antes e sobre o que eles aprenderam depois da vivência do jogo. 


\section{Conclusões}

Diante do exposto, observa-se que é viável a utilização de jogos didáticos nas aulas de Química, pois melhora a compreensão do conceito, como, também a aula torna-se mais interativa e divertida. Portanto, a teoria pode ser ministrada em conjunto com práticas que despertem o interesse e a participação dos alunos nas aulas.

Esse tipo de atividade apresenta um diferencial frente a outras já conhecidas no meio da comunidade de profissionais voltados ao Ensino de Química no Brasil, pois além dos jogos serem elementos muito rico no processo de apropriação do conhecimento, permitindo o desenvolvimento de competências no meio comunicacional, das relações interpessoais (interação), da liderança e do trabalho em equipe, pois o aluno coopera com os colegas de equipe e compete com as outras equipes que são formadas pelos demais colegas da turma, na nossa proposta, o Ciclo da Experiência Kellyana, auxilia no processo de engajamento e aprendizagem.

O MemOxi obteve-se resultados satisfatórias, pois os estudantes entenderam os grupos funcionais das funções oxigenadas, associando a estrutura, nomenclatura e o grupo funcional, isso afirma que esse jogo é um material inovador que contribui positivamente para o processo de ensino e aprendizagem dos estudantes do ensino médio no conteúdo de "Química Orgânica - Funções Oxigenadas" na disciplina de Química.

\section{Referências}

BRASIL. Secretaria de Educação Média e Tecnologia, Ministério da Educação. Ciências da Natureza, Matemática e suas Tecnologias. In: Parâmetros Curriculares Nacionais do Ensino Médio. Brasília, 1999.

CRUTE, T. D. Classroom nomeclature Games- BINGO. Journal of Chemical Education, v.77, n.4, p.481, 2000

EICHLER, M.; DELPINO, J.C. Carbópolis, um software para Educação Química. Química Nova na Escola. n.11, xxp., 2000.

KELLY, A.G. A theory of personality: the psychology of personal constructs. New York: W.W. Norton, 1963.

KISHIMOTO, T. M.O jogo e a educação infantil. São Paulo: Pioneira, 2002. - (KISHIMOTO, 2002).

SANTOS, D. O.; SANTANA, R. J.; ANDRADE, D.; LIMA, P. S. Experimentação: contribuições para o processo de ensino aprendizagem do conteúdo de Cinética Química. (Santos et al., 2004).

SANTANA, E.M.; WARTHA, E. J. O Ensino de Química através de jogos e atividades lúdicas 
baseados na teoria motivacional de Maslow. In: ENCONTRO NACIONAL DE ENSINO DE QUÍMICA, 13, Campinas (Unicamp), 2006. Anais, Campinas - São Paulo, 2006.

SOARES, M.H.F.B.; OKUMURA, F; CAVALHEIRO, E.T.G. Proposta de um jogo didático para ensinar o conceito de equilíbrio químico. Química Nova na Escola, n.18, p.13, 2003.

VIEIRA, W. E. S.; MELO, H. D. F.; NASCIMENTO, A. M. S.; VIANA, K. S. L.; UNOPeriódico como estratégia lúdica para aprendizagem em Química. In: I Simposio Latinoamericano en Formación de Profesores: Tecnología y Educación, Valparaíso, Chile, 2016. Resúmenes I Simposio Latinoamericano en Formación de Profesores: Tecnología y Educación 